\title{
Quantitative Estimation of the Ecosystem Services Supporting the Growth of Japanese Chum Salmon
}

\author{
Yuka Karasawa $^{1}$, Hiromichi Ueno ${ }^{1}$, Ryo Tanisugi ${ }^{1}$, Ryo Dobashi ${ }^{1}$, Seokjin Yoon ${ }^{2}$, Akihide Kasai ${ }^{1}$, and \\ Masashi Kiyota ${ }^{3}$
}

${ }^{1}$ Graduate School/Faculty of Fisheries Sciences, Hokkaido University, 3-1-1 Minato-cho, Hakodate, Japan

${ }^{2}$ National Institute of Fisheries Science, Gijanghaean-ro, Gijang-eup, Busan 46083, Korea

${ }^{3}$ Graduate School of Fisheries and Environmental Sciences, Nagasaki University, Japan

Keywords: Ecosystem services, Japanese chum salmon, bioenergetics model, lower trophic level ecosystem model

Japanese stocks of chum salmon (Oncorhynchus keta) are released in spring, spend several months near the coast of Japan, then migrate to the Okhotsk Sea, where they remain until late fall (Urawa 2000; Azumaya and Ishida 2004) (Fig. 1). The fish then migrate toward the western North Pacific, where they overwinter, then migrate into the Bering Sea by the following summer. In the fall, they move into the Gulf of Alaska in the eastern North Pacific, where they spend one winter. They repeat the migration track between the Bering Sea (summer) and the Gulf of Alaska (winter) 3-4 times, and then return to Japan when approaching maturity in the summer of their fourth to fifth year.

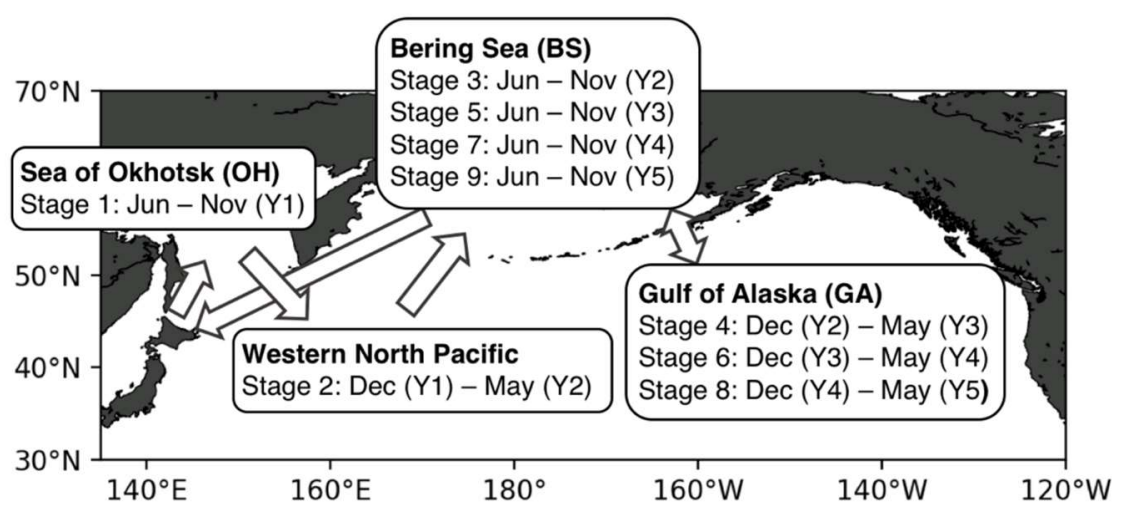

Fig. 1. Japanese chum salmon migration path, duration of stay en route and life stages. Y1, Y2, Y3, Y4, and Y5 indicate Years 1, 2, 3, 4, and 5, respectively. Adopted from Karasawa et al (2020).

Salmon provide provisioning, culture, and supporting services for human populations. However, salmon are themselves also supported by the ecosystem services provided by their habitat, which are called "supporting services" or "habitat services" (TEEB 2010). The ecosystem providing the reproduction habitat for commercially valuable species provides an important so-called "nursery-service," which is (economically) valued in its own right (TEEB 2010). However, it is difficult to evaluate the monetary value of supporting services from the ecosystem when they are not traded on the market. In this case, revealed preference or stated preference approaches are used, but both approaches have limitations (TEEB 2010). As for salmon, their growth and survival are dependent on the supply of appropriate prey and their habitat in the ocean, which we regard here as supporting services for salmon. However, a means for quantitatively estimating supporting services for salmon in oceans has yet to be developed.

In this study (Karasawa et al. 2020), we focused on the prey consumption, growth and survival of Japanese chum salmon, and developed a method that quantitatively estimates the supporting services for the growth of Japanese chum salmon using a bioenergetics model coupled with a lower trophic level ecosystem model (NEMURO: North Pacific Ecosystem Model for Understanding Regional Oceanography; Kishi et al. 2007). We estimated the prey biomass consumed by a cohort of Japanese chum salmon, defined as a group of Japanese chum salmon released in a single year. The phytoplankton biomass indirectly consumed by this cohort was also estimated (Fig. 2); this was considered to be the primary production supporting the fish. We also attempted to calculate the monetary value of supporting services for the growth of Japanese chum salmon.

Our model estimates showed that a cohort of Japanese chum salmon consumed in total ca. $4.2-4.7 \times 10^{9} \mathrm{~kg}$ wet weight of zooplankton during Stages 1-9, and that the cohort indirectly consumed $2.0-2.2 \times 10^{9} \mathrm{~kg} \mathrm{C}$ of primary production, which amounted to $0.17-0.19 \%$ of primary production in the areas and periods through which the salmon migrated. Thus, a cohort of artificially released Japanese chum salmon was supported by $2.0-2.2 \times 10^{9}$ $\mathrm{kg} \mathrm{C}$ of primary production during Stages 1-9. This is the production that supports the human harvest of a cohort. Although we applied the model similarly to previous studies examining the impact of environmental variability on

All correspondence should be addressed to H. Ueno. 
the growth of Japanese chum salmon, including studies that predicted future scenarios (Kamezawa et al. 2007; Kishi et al. 2010; Yoon et al. 2015), this is the first attempt to estimate the supporting services for these fish.

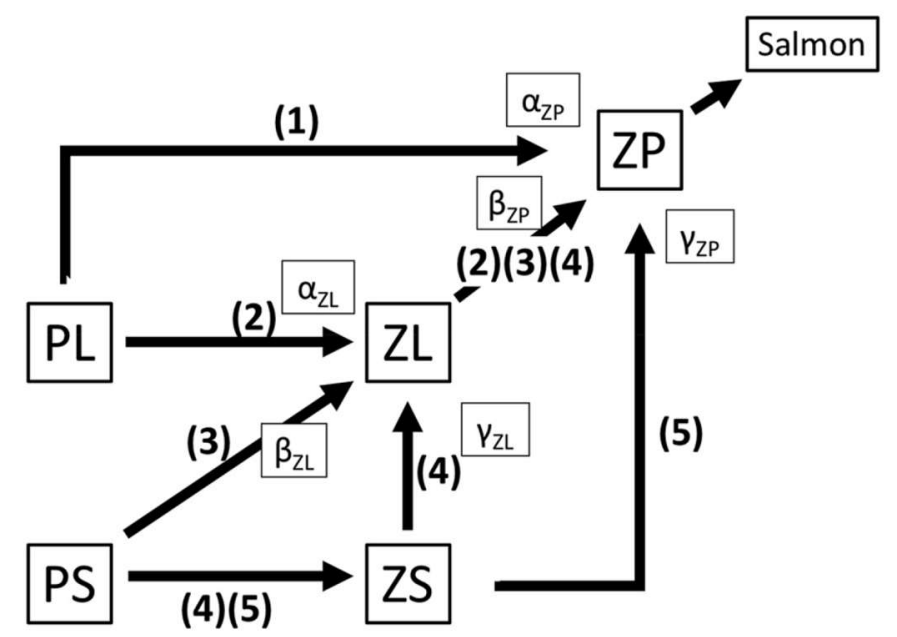
Fig. 2. Diagram of the NEMURO model showing transfer paths of organic matter from PL (large phytoplankton) and PS (small phytoplankton) to ZP (predatory zooplankton). Arrow (1) indicates a direct path from PL to ZP, arrow (2) is a pathway from PL to ZP via ZL (large zooplankton), arrow (3) is a pathway from PS to ZP via ZL, arrow (4) is a pathway from $P S$ to $Z P$ via $Z S$ and $Z \mathrm{~L}$, and arrow (5) is a pathway from PL to $Z P$ via $Z S$. $\alpha Z P, \beta_{Z P}, \gamma_{Z P}$ and $\alpha_{Z L}, \beta_{Z L} \gamma_{Z L}$ are the ratios of prey consumed by ZP and ZL, respectively. Karasawa et al (2020).

It is possible to extend our new approach to briefly consider the monetary value of supporting services for the growth of Japanese chum salmon. As an example, we calculated the monetary value of ZP consumed by Japanese chum salmon assuming that the monetary value of ZP is equivalent to that of krill. Krill is an important component of ZP in NEMURO (Kishi et al. 2007), and it is also traded in the Japanese commercial market. We used the average price in the Tokyo Metropolitan Central Wholesale Market for the period 2002-2018 (http://www.shijoutokei.metro.tokyo.jp/index.html), i.e., 476 Japanese yen $\mathrm{kg}^{-1}$ wet weight. Using the market price of krill, the total value of ZP consumed by Japanese chum salmon was estimated to be $2.0-2.2 \times 10^{12}$ Japanese yen $\left(0.1 \times 10^{12}, 0.2 \times\right.$ $10^{12}, 1.0-1.1 \times 10^{12}$, and $0.7-0.8 \times 10^{12}$ Japanese yen in the Sea of Okhotsk, the western North Pacific, the Bering Sea and the Gulf of Alaska, respectively). These values were estimated considering the interannual variation in age composition (i.e., the percentage of fish returning to Japan at Stages 5 and 7 varied from 50\% to 75\%). The sum total (18-20 $\times 10^{9}$ US dollars based on the exchange rate in 2018) far exceeds the value of the Japanese chum salmon harvest $\left(0.06 \times 10^{12}\right.$ Japanese yen or $0.5 \times 10^{9}$ US dollars averaged over the period 2001-2017). Thus, the harvest of $c a .0 .06 \times 10^{12}$ Japanese yen was supported by a shadow cost (prey) of up to 2.0-2.2 $\times 10^{12}$ Japanese yen.

\section{REFERENCES}

Azumaya, T., and Y. Ishida. 2004. An evaluation of the potential influence of SST and currents on the oceanic migration of juvenile and immature chum salmon (Oncorhynchus keta) by a simulation model. Fish. Oceanogr. 13: 10-23.

Kamezawa, Y., T. Azumaya, T. Nagasawa, and M.J. Kishi. 2007. A fish bioenergetics model of Japanese chum salmon (Oncorhynchus keta) for studying the influence of environmental factor changes. Bull. Japan. Soc. Fish. Oceanogr. 71: 87-96. (In Japanese with English abstract)

Karasawa, Y., H. Ueno, R. Tanisugi, R. Dobashi, S. Yoon, A. Kasai, and M. Kiyota. 2020. Quantitative estimation of the ecosystem services supporting the growth of Japanese chum salmon. Deep-Sea Res. II 175: 104702. doi.org/10.1016/j.dsr2.2019.104702.

Kishi, M.J., M. Kashiwai, D.M. Ware, B.A. Megrey, D.L. Eslinger, F.E. Werner, and 22 et al. 2007. NEMUROA lower trophic level model for the North Pacific marine ecosystem. Ecol. Model. 202: 12-25.

Kishi, M.J., M. Kaeriyama, H. Ueno, and Y. Kamezawa. 2010. The effect of climate change on the growth of Japanese chum salmon (Oncorhynchus keta) using a bioenergetics model coupled with a three-dimensional lower trophic ecosystem model (NEMURO). Deep-Sea Res. II 57: 1257-1265.

TEEB. 2010. The Economics of ecosystems and biodiversity: ecological and economic foundations. Edited by Pushpam Kumar. Earthscan, London and Washington. 456 pp.

Urawa, S. 2000. Migration route and future works of Japanese salmon. Nat. Salmon Resources Center Newsletter 5: 3-9. (In Japanese)

Yoon, S., E. Watanabe, H. Ueno, and M.J. Kishi. 2015. Potential habitat for chum salmon (Oncorhynchus keta) in the Western Arctic based on a bioenergetics model coupled with a three-dimensional lower trophic ecosystem model. Prog. Oceanogr. 131: 146-158. 